\title{
Social plasticity in fish: integrating mechanisms and function
}

\author{
R. F. OLIVEIRA*†† \\ *Unidade de Investigação em Eco-Etologia, ISPA - Instituto Universitário, Rua Jardim do \\ Tabaco 34, 1149-041 Lisboa, Portugal and †Champalimaud Neuroscience Programme, \\ Instituto Gulbenkian de Ciência, Rua da Quinta Grande 6, 2780-156 Oeiras, Portugal
}

\begin{abstract}
Social plasticity is a ubiquitous feature of animal behaviour. Animals must adjust the expression of their social behaviour to the nuances of daily social life and to the transitions between life-history stages, and the ability to do so affects their Darwinian fitness. Here, an integrative framework is proposed for understanding the proximate mechanisms and ultimate consequences of social plasticity. According to this framework, social plasticity is achieved by rewiring or by biochemically switching nodes of the neural network underlying social behaviour in response to perceived social information. Therefore, at the molecular level, it depends on the social regulation of gene expression, so that different brain genomic and epigenetic states correspond to different behavioural responses and the switches between states are orchestrated by signalling pathways that interface the social environment and the genotype. At the evolutionary scale, social plasticity can be seen as an adaptive trait that can be under positive selection when changes in the environment outpace the rate of genetic evolutionary change. In cases when social plasticity is too costly or incomplete, behavioural consistency can emerge by directional selection that recruits gene modules corresponding to favoured behavioural states in that environment. As a result of this integrative approach, how knowledge of the proximate mechanisms underlying social plasticity is crucial to understanding its costs, limits and evolutionary consequences is shown, thereby highlighting the fact that proximate mechanisms contribute to the dynamics of selection. The role of teleosts as a premier model to study social plasticity is also highlighted, given the diversity and plasticity that this group exhibits in terms of social behaviour. Finally, the proposed integrative framework to social plasticity also illustrates how reciprocal causation analysis of biological phenomena (i.e. considering the interaction between proximate factors and evolutionary explanations) can be a more useful approach than the traditional proximate-ultimate dichotomy, according to which evolutionary processes can be understood without knowledge on proximate causes, thereby black-boxing developmental and physiological mechanisms.

(C) 2012 The Author
\end{abstract}

Journal of Fish Biology (c) 2012 The Fisheries Society of the British Isles

Key words: cognitive appraisal; immediate early genes; social behaviour network; social learning; transcriptome.

\section{INTRODUCTION}

Social living organisms have to closely monitor their social environment and finetune their behaviour according to previous social experience and social context (available public information), in order to avoid the costs of engaging in social 
interactions or being ejected from their social groups (Oliveira, 2009). This ability of animals to regulate the expression of their social behaviour in order to optimize their social relationships (social plasticity) should be viewed as a performance trait (Arnold, 1983; Irschick et al., 2008) that affects the Darwinian fitness of the animal (Oliveira, 2009). In terms of behavioural mechanisms, social competence relies on behavioural plasticity at different temporal scales: (1) life-cycle staging or developmental plasticity, when plasticity is seasonally cyclic, such as changes in behaviour between different life-history stages (e.g. breeding $v$. non-breeding) and (2) behavioural flexibility, when behavioural change occurs in the short term (i.e. within the same life-history stage) and is reversible (Piersma \& Drent, 2003; Kappeler \& Kraus, 2010). In this article, the terms behavioural flexibility or social flexibility will be used when referring to short-term labile social behaviour changes, and developmental plasticity when specifically addressing long-term irreversible changes in social behaviour. Whenever the term social plasticity is used, it refers to adaptive changes in the expression of social behaviour at both time scales.

Despite its biological relevance, the study of social plasticity has been neglected and only in recent years has it attracted the attention of behavioural ecologists (Smiseth et al., 2008; Dingemanse et al., 2010, 2012; Westneat et al., 2011). There are important evolutionary implications, however, of social phenotypic plasticity: (1) plasticity can be seen as a constraint that slows down evolution (Pigliucci, 2005),

(2) it can give rise to directional selection if plasticity is too costly or incomplete (DeWitt et al., 1998; Price et al., 2003), (3) plasticity in itself can be seen as a trait that can be under positive selection in heterogeneous environments, where direct genetic control over the phenotype is outpaced by the rate of environmental change (West-Eberhard, 1989; DeWitt et al., 1998; Pigliucci \& Hayden, 2001; Price et al., 2003; Pigliucci, 2005) and (4) given the singular role of the nervous system in orchestrating flexible responses to cues that signal environmental change, the understanding of the ultimate and proximate mechanisms of social plasticity is crucial for understanding behaviour and brain evolution (e.g. social brain hypothesis; Dunbar \& Shultz, 2007).

Here, the development of an integrative approach is proposed for understanding social plasticity that integrates the study of proximate (gene modules, hormones and neural circuits) and ultimate (evolutionary consequences) mechanisms, and teleosts are presented as a premier vertebrate group to address 'why' and 'how' questions regarding social plasticity across different levels of biological organization.

\section{AN INTEGRATIVE CONCEPTUAL FRAMEWORK FOR STUDYING SOCIAL PLASTICITY}

The integrative approach proposed here is based on the emerging idea that in order to understand behaviour it is necessary to integrate the study of mechanisms (i.e. behavioural neuroscience) into the study of function (i.e. behavioural ecology), so that functional explanations of behaviour do not assume a phenotypic space with unlimited degrees of freedom and that the evolution of simple rules that must govern adaptive behaviour is understood. This 'evo-mecho' framework (McNamara \& Houston, 2009) to social plasticity has the following premises (Fig. 1): (1) In order to adjust the expression of behaviour to changes in the social environment, animals have 


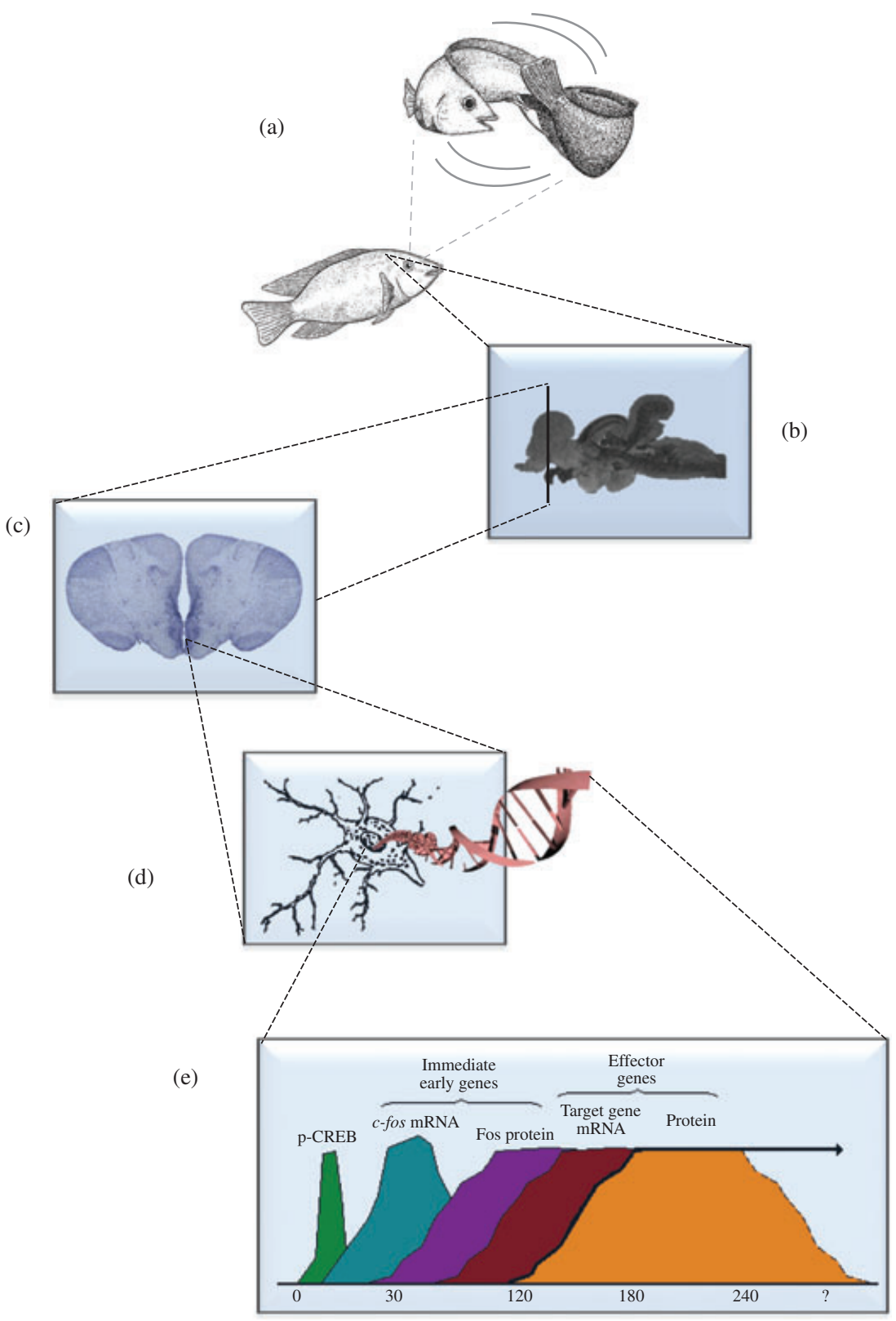

FIG. 1. Mechanisms of social plasticity: (a) social living animals adjust the expression of their behaviour to social information collected in previous social interactions or by observing others; (b) the cognitive appraisal of this information allows them to evaluate the stimulus or event in terms of its valence and salience that will be encoded in a distributed neural network; (c) at each node of this network; (d) neurons will change their neurogenomic state, i.e. their gene expression profile in response to the perceived social information; and (e) changes of gene expression are triggered by the activation of neuronal activity-regulated transcription factors (e.g. p-cAMP response element-binding) that regulate immediate early genes (e.g. c-fos) which can regulate synaptic proteins (e), thereby modulating neural plasticity that underlies behavioural flexibility. 
to constantly monitor the environment and collect relevant social cues from direct interactions with other animals or from public sources of information (i.e. social learning; Galef \& Laland, 2005). Given the wide array of social signals conveyed in multiple sensory modalities, it is postulated that a general appraisal mechanism that assesses the valence and salience of social stimuli across different sensory modalities and functional domains must operate (Paul et al., 2005; Mendl et al., 2010). Thus, the cognitive appraisal of social information collected either directly or indirectly will determine the expression of the appropriate behaviour, given the perceived properties of the social stimulus. (2) Cognitive appraisal of social stimuli triggers neuronal activity-dependent mechanisms at the molecular and cellular level that result in different forms of neural plasticity depending on the duration of the exposure to relevant social signals. In the short term, transient socially driven neuroplasticity can be achieved by three different neuronal activity-dependent mechanisms (Aubin-Horth \& Renn, 2009; Wolf \& Linden, 2012): (a) activation (e.g. phosphorylation) of proteins that act as transcription factors [e.g. cyclic adenosine monophosphate (cAMP) response element-binding (CREB)] for immediate early genes (IEG) or for delayed response genes or regulate intracellular signalling pathways [e.g. mitogen-activated protein kinases (MAPK) pathway], (b) neuronal activity-dependent transcription factors (e.g. pCREB) activate IEGs that can encode other transcription factors (e.g. c-fos and egr-1) or synaptic proteins (Arc and Homer1a), hence acting as neuromolecular switches that change the expression of co-regulated gene sets in the brain and (c) transcription of microRNAs that regulate translation of synaptic proteins (e.g. miR-134). At the long term, socially driven long-lasting changes in social behaviour or plasticity rely on epigenetic modifications (e.g. DNA methylation and histone modifications) of genes involved in social behaviour [e.g. oxytocin (OT) and vasopressin (AVP)] or neural plasticity (e.g. bdnf and npas4) (Champagne \& Curley, 2005; Szyf et al., 2008; Curley et al., 2011). Together, these neuronal activity-dependent mechanisms change the neurogenomic state of the brain in response to perceived social stimuli. (3) Neural circuits underlying behaviour are composed of a network of brain nuclei with reciprocal connections between each pair (the brain social behaviour network, SBN; Newman, 1999; Goodson, 2005) that encodes information in a distributed and dynamic fashion, such that the expression of a given behaviour is better reflected by the overall profile of activation across the different loci in the network than by the activity of a single node. Different combinations of activation across nodes, and variation in the strength of the connections among them, will generate an almost infinite variation in social behaviour. Therefore, the changes in neurogenomic states mentioned in the previous point can occur differentially at each of the nodes of the SBN, and social plasticity relies both on temporal and spatial changes in gene regulation in the neural networks. (4) Hormones (i.e. sex steroids and glucocorticoids) and neuromodulators (i.e. neuropeptides and amines) can change the weight of each node of the SBN, and the strength of the connectivity between them, allowing the integration of global organismic state in social decision-making and co-ordinating brain-body responses to changes in the social environment and to transitions between life-history stages (Oliveira, 2009). The actions of hormones and neuromodulators may occur at different frameworks depending on the receptors used to translate the signal. For example, steroids can act as transcription factors by binding to nuclear receptors or have more rapid non-genomic effects on the cell by acting on membrane receptors (McEwen, 1991; Moore \& Evans, 1999). (5) The 
molecular, neural and hormonal mechanisms mentioned above allow the animal to adjust its behavioural output according to the perceived social environment, resulting in transient (i.e. behavioural flexibility) or long-lasting (i.e. behavioural consistency, 'animal personalities'; Dingemanse et al., 2010) changes in social behaviour (social plasticity). (6) The organism's ability to switch between social phenotypes in order to optimize its social relationships will increase its Darwinian fitness and can be seen as an organismal performance trait. If there is genetic variation underlying social plasticity, it can come under directional selection and evolve within limits imposed by costs and constraints.

According to this framework, social plasticity is achieved by rewiring or by biochemically switching nodes of the neural network underlying social behaviour in response to perceived social information. Therefore, at the molecular level, it depends on the social regulation of gene expression, so that different neurogenomic states correspond to different behavioural responses and the switches between states are orchestrated by signalling pathways that interface the social environment and the genotype. At the evolutionary scale, social plasticity can be seen as an adaptive trait that can be under positive selection when changes in the environment outpace the rate of genetic evolutionary change. In cases when social plasticity is too costly or incomplete, behavioural consistency can emerge by directional selection that recruits gene modules corresponding to favoured behavioural states in that environment. Therefore, this framework also provides a unifying theory to explain social diversity across different biological levels: social diversity may occur within species, if the weights of each node in the network have a genetic and epigenetic component, giving rise to different social phenotypes, or between species, if the weighting changes with evolution.

\section{TELEOSTS AS VERTEBRATE MODEL SYSTEMS FOR THE STUDY OF SOCIAL PLASTICITY}

Krogh (1929) achieved great popularity in the biological literature by highlighting the importance of choosing the right organism in the design of biological experiments. His famous statement that 'for a large number of problems there will be some animal of choice, or a few such animals, on which it can be most conveniently studied' became subsequently known as the Krogh principle (Krebs, 1975). Thus, ideally the choice of the study organism should be based not only on its availability to the researcher (e.g. classic model organisms such as mice Mus musculus, the fruit fly Drosophila melanogaster and nematode Caenorhabditis elegans), but rather on its properties that will facilitate the understanding of the biological process of interest. The application of Krogh's principle to the study of social plasticity rapidly leads to the identification of teleosts as the most promising model systems among vertebrates.

Within vertebrates, teleosts are the most diverse and plastic taxa in terms of social behaviour. With over 29000 species described so far, all the different types of social organization, mating systems and parental care types (Froese \& Pauly, 2012) can be found, and it is relatively common to find variation of these characters within closely related groups of species which offers a unique opportunity for comparative studies on the evolution of social behaviour (e.g. variation in mating systems and parental care type in African cichlids; Kornfield \& Smith, 2000). Fishes are also champions of behavioural and phenotypic plasticity, as can be illustrated by the flexible 
patterns of sexual expression, as in the case of protandrous and protogynous sex change, simultaneous hermaphroditism and intra-sexual variation in the form of discrete alternative male phenotypes (Oliveira et al., 2005a; Taborsky, 2008; Desjardins \& Fernald, 2009; Godwin, 2010). Furthermore, highly social species with complex social behaviour that requires advanced cognitive abilities have also evolved in fishes (e.g. transitive inference in social interactions; Grosenick et al., 2007). A particularly well-studied case is the cleaning mutualism between obligatory bluestreak cleaner wrasse Labroides dimidiatus (Valenciennes 1839) and the so-called client fish, in which cleaners present an array of behaviours, including categorization, deception, punishment, reconciliation, partner choice, manipulation and social prestige, that in primates have been seen as indicators of Machiavellian intelligence (Bshary et al., 2002; Bshary, 2011). Such cognitive abilities most probably underlie socially driven plasticity in fish social behaviour. Prior experience effects on social behaviour are one of the most studied examples of social plasticity. The outcome of social interactions influences the expression of subsequent social behaviour, so that individuals that win an interaction increase their probability of winning a subsequent interaction and vice versa for losers (Oliveira et al., 2009). These winner and loser effects are widespread across different animal taxa, including many fish species, with the magnitude of loser effects being, in general, higher than that of winner effects and frequently lasting longer (Hsu et al., 2006; Rutte et al., 2006). Losing effects can be so profound that in a recent study in D. melanogaster a single loss was shown to overcome the effects of artificial selection for aggressiveness (Penn et al., 2010). In parallel to winning and losing effects, prior experience can also promote the occurrence of redirected aggression, a phenomenon usually ascribed to primates that has also been described in fishes (Øverli et al., 2004). On the other hand, animals also modify their social behaviour depending on social context, such as the presence of an audience, observing third-party interactions (bystander effect) or the familiarity with the opponent (dear enemy effects), and all these contextual effects on behaviour have been shown to be mediated by socially modulated changes in neuroendocrine function (Oliveira et al., 2001; Aires et al., 2004; Dzieweczynski et al., 2006).

In parallel with the above-mentioned behavioural characteristics that make them targets for research on social plasticity, their use for studies that aim to uncover general mechanisms underlying social plasticity is also enhanced by the fact that the neural and gene networks involved in social behaviour seem to be significantly conserved across vertebrates (O’Connell \& Hofmann, 2011, 2012). For example, despite the divergent brain development programmes between actinopterygians and other vertebrates, where in the former group the pallial regions undergo an incomplete eversion, contrary to the inversion process observed in those of the latter group (Striedter \& Northcutt, 2006), the brains of both groups present a high degree of functional homology (Wullimann \& Mueller, 2004; Broglio et al., 2005). Similarly, despite the fish-specific genome duplication event observed early in the radiation of actinopterygians (Meyer \& Van de Peer, 2005), neurochemical genes relevant for social behaviour [e.g. sex steroid receptors, genes of the AVP-like nonapeptides and their receptors and genes of the dopaminergic (DA) system] and their regional expression across brain areas relevant for social behaviour are both well conserved (O’Connell \& Hofmann, 2011, 2012).

Finally, a number of social fish species exhibit a set of characteristics that make them interesting model systems: (1) they are in general easier to breed and keep in the 
laboratory than other vertebrate animal models, (2) the production of large numbers of offspring, a short inter-generation time and their small size that allows to keep large numbers in captivity and to have many replicates in a research area where the social group, rather than the individuals is often the sampling unit and (3) their social systems can be easily replicated and manipulated in captivity (e.g. inducing social status reversals by manipulating group composition), so that more naturalistic social settings are achieved and social behaviour is more readily expressed.

There are, however, still some limitations to the use of fish models in social plasticity research, mainly related to the status of current technology. Namely, neuroanatomy and genetic tools are not readily available for non-model organisms that display relevant patterns of social plasticity (e.g. species with alternative behavioural tactics), and the use of brain imaging techniques (e.g. calcium imaging and magnetic resonance imaging), although becoming available in fishes, still implies the physical restriction of the focal individuals (Van der Linden et al., 2004; Ahrens et al., 2012). Nevertheless, for a smaller number of teleost model organisms [e.g. zebrafish Danio rerio (Hamilton 1822) and medaka Oryzias latipes (Temminck \& Schlegel 1846)] a large number of genetic tools and resources are becoming available, ranging from commercial genome microarrays and chromatin immunoprecipitation (CHIP)-on-chip tiled microarrays to GAL4-UAS (gal4-upstream activation sequence) transgenic lines that allow genetic manipulation of specific neural circuits or candidate genes (Muto \& Kawakami, 2011), and new comparative genomic tools e.g. methods for heterologous microarrays (Machado et al., 2009; RNA sequencing, Wang et al., 2009) are allowing the study of non-classic model systems.

In summary, teleosts offer a singular opportunity to study both proximate mechanisms (i.e. genes, neurochemicals and brain circuits) and evolutionary consequences of social plasticity.

\section{COGNITIVE LANDSCAPES OF SOCIAL PLASTICITY: COGNITIVE APPRAISAL AND SOCIAL LEARNING}

Social plasticity requires that animals identify and respond to reliable social information that signals changes in the social environment. Social information can be available in multiple sensory channels and can be collected first-hand by directly interacting with other individuals, or by observing other behavioural agents (i.e. social learning). Thus, animals have to continuously sense and integrate multiple sensory inputs and extract key characteristics of the social environment from them. Therefore, at the cognitive level, social plasticity relies on some kind of general appraisal mechanism that allows organisms to evaluate the stimuli using a set of stimulus checks to assess its valence and salience in its putative multiple sensory dimensions, in order to determine the appropriate behavioural response (Paul et al., 2005; Mendl et al., 2010). Cognitive appraisal theory proposes that a response to a stimulus is not just a result of direct effects of perceptual information, but rather a function of what that perceptual information means to the organism at that moment of time (Lazarus, 1991; Scherer, 2001). A set of stimulus evaluation checks (SEC) has been proposed (Scherer, 2001) that are also likely to occur in non-humans (Mendl et al., 2010). Examples of these include suddenness, familiarity, predictability, intrinsic pleasantness, discrepancy from expectation and capacity for control (Scherer, 2001; Mendl et al., 2010). Despite the fact that some of these checks have been described 
in animals (e.g. predictability in fishes; Galhardo et al., 2011), a systematic study of SECs and their neural underlying mechanisms in animals is still lacking. According to Lazarus (1991), one of the founders of the appraisal theory, two major types of appraisal occur: (1) primary appraisal, that evaluates the significance of the event to the organism and (2) secondary appraisal, that assesses the ability of the organism for coping with the perceived consequences of the event. These two types of appraisal interact with each other in defining the outcome of appraisal that can be a direct action or a cognitive reappraisal process (Lazarus, 1991). The SECs mentioned above are part of these two processes, with intrinsic valence, novelty (as defined by suddenness, familiarity and predictability) and prediction error related to primary appraisal and controllability to secondary appraisal. In summary, cognitive appraisal is expected to play a key role in the translation of relevant environmental social cues into organismal signals that trigger plasticity.

The study of cognitive appraisal in fishes is still vestigial. One approach that has been used to test the idea that it is the individuals' appraisal of the social event rather than its objective structure that triggers the biological response (Oliveira et al., $2005 b$ ) is to study the response of fishes to mirror-elicited fights. As fishes do not recognize their own image in a mirror, they attack it as if it is an intruder (Rowland, 1999). Mirror fights offer a possibility to study appraisal as there is a decoupling between the expression of behaviour and the behavioural feedback from the interaction that allows the individuals to make an assessment of its outcome. In other words, despite the fact that aggressive behaviour is being expressed at levels similar to those present in real opponent fights (Oliveira et al., 2005b), the participant does not experience either a win or a defeat in this type of interactions. So, the prediction is that if an assessment of the interaction outcome is needed to trigger a physiological response, then it should not be present in mirror-elicited interactions. On the other hand, if the activation of the biological response is simply triggered by the activation of the behavioural response (i.e. expressing fighting behaviour), then it is expected to be present both in real opponent and mirror fights. So far, this hypothesis has been tested in three cichlids and in quail Coturnix japonica, with mixed results: hormonal responses to mirror-elicited fights are present in two cichlid species (Desjardins \& Fernald, 2010; Dijkstra et al., 2012) and absent in the other cichlid (Oliveira et al., 2005 b) as well as in C. japonica (Hirschenhauser et al., 2008). As there are methodological differences between some of these studies (Oliveira \& Canario, 2011), the results are so far inconclusive and further comparative research with standardized methods is needed to clarify this hypothesis. Interestingly, in the anole lizard Anolis carolinensis, in which the darkening of postorbital skin eyespots signals sympathetic activation and social dominance, a series of mirror-elicited studies that manipulated eye spot darkening provide evidence that the physiological response of A. carolinensis towards mirror images varies with the information content of the image (i.e. colour of eyespot; Korzan et al., 2000a, b, 2001). As in these experiments, the painting of the eyespots decoupled the activation of the signal in the focal animal from the observed signal in the mirror image, it allowed the focal animal to assess its fighting ability relative to the different mirror images and to respond accordingly. Therefore, these results can also be interpreted as supporting the role of cognitive appraisal in the activation of physiological responses.

In summary, cognitive appraisal allows the classification of social stimuli regarding their valence, salience and the organism capacity for control, which will reduce the 
perception of the complexity of the social environment to key dimensions that will enable the animal to identify ecological opportunities and challenges and to trigger a flexible response by decoupling stimulus and response.

Social environments also offer the possibility to use information that is produced by others (i.e. social learning) in order to identify opportunities and challenges that will trigger social plasticity. This allows naive individuals to acquire adaptive information without having to incur in the costs and risks associated with exploring the environment to learn about its contingencies (Dukas, 1999; Galef \& Laland, 2005; Burns et al., 2011). Thus, animals living in social groups are expected to have evolved social learning abilities, and these have been widely described in fishes in different evolutionary relevant domains, such as predator evasion (Arai et al., 2007), foraging (Swaney et al., 2001), mate choice (Witte \& Nöbel, 2011) or social eavesdropping in territorial systems (Peake \& McGregor, 2004; Brown \& Laland, 2011). The use of social information can be seen as part of the social plasticity repertoire of social species as there is a trade-off between the use of costly but accurate personal information and the use of cheap but potentially less reliable public information, so that an explanation of social learning should not be invoked indiscriminately. Thus, social learning rules must dictate when to copy others and who to copy (Laland, 2004; Kendal et al., 2009).

Despite the extensive work on ecological and evolutionary aspects of social learning in fishes, its behavioural and neural mechanisms have been much less studied. In an attempt to create a framework for the study of the mechanisms of social learning, a correspondence between different forms of social learning and categories of asocial learning has been proposed: local or stimulus enhancement and single stimulus learning (sensitization or habituation), observational conditioning and Pavlovian conditioning and copying or imitation and operant conditioning, respectively (Heyes, 1994). Unlike asocial learning, however, where the learning signal is the difference between predicted and obtained outcomes (i.e. prediction error), social learning cannot be based on directly experienced prediction errors (Burke et al., 2010). Therefore, the mechanisms of observational learning have remained elusive (but a new form of observational prediction error has been proposed recently that would act as a learning signal based on externally observed information; Burke et al., 2010) and are a promising avenue for research.

In summary, cognitive appraisal of social information and social learning are cognitive skills that are expected to play a key role in social plasticity.

\section{NEURAL AND ENDOCRINE LANDSCAPES FOR SOCIAL PLASTICITY: THE SOCIAL DECISION-MAKING NETWORK}

At the neural level, social plasticity relies on a social decision-making network that is composed of at least two interconnected neural circuits, that have been conserved across vertebrates as it can be seen from the conserved patterns of expression of developmental genes and neurochemical systems in the telencephalon: (1) the basal forebrain reward system and (2) the SBN (O'Connell \& Hofmann, 2011).

A reward system is needed for social decision-making as it enables the evaluation of stimulus valence and salience and the reinforcement of adaptive behaviours through natural rewards that can act either as reinforcers or as hedonic incentives 
(Kelley \& Berridge, 2002). In mammals, natural rewards are processed by the DA mesolimbic system composed of DA neurons located in the ventral tegmental area (VTA) that project rostrally to the nucleus accumbens, amygdala (AMY) and prefrontal cortex. This mesolimbic reward system has also been subsequently described in birds and reptiles but in anamniotes a midbrain DA population similar to the VTA is missing (Smeets et al., 2000). Afterwards, the identification of DA neurons in the ventral diencephalon, in particular in the posterior tuberculum, that project towards the subpallium (Rink \& Wullimann, 2001, 2002), raised the hypothesis that this ascending DA pathway might be homologous to the mammalian mesostriatal DA pathway. More recently, however, data on the expression of developmental factors and a more detailed projectome of DA neurons in larval $D$. rerio have made clear that the ventral diencephalic DA groups in $D$. rerio that have ascending projections to the telencephalon (i.e. DA groups DC2 and DC4) are specified by a conserved transcriptional network also present in the A11 mammalian diencephalic DA cell group (Lohr et al., 2009), but not shared by the midbrain mammalian DA group (i.e. A10), and that most subpallial DA inputs originate in a local subpallial DA system that also connects to the ventral telencephalon (Tay et al., 2011). Therefore, although the ventral diencephalic DA neurons play a major role in the neuromodulation of behavioural flexibility, they cannot be seen as homologous to the mammalian VTA DA neurons that apparently emerged later in the evolution of DA modulatory systems (Yamamoto \& Vernier, 2011).

Newman (1999) originally proposed the existence of the SBN that is involved in the regulation of multiple forms of social behaviour (aggression, affiliation, bonding, parental behaviour and social stress) and includes the extended medial AMY, the lateral septum, the preoptic area, the anterior hypothalamus, the ventromedial hypothalamus and the periaqueductal grey in mammals. The presence of the SBN has been confirmed across all vertebrate classes, using the expression of IEGs as markers of neural activity in relation to the expression of different social behaviours (e.g. social communication, aggression and courtship; Goodson, 2005). Other networks for different tasks have also been identified (e.g. for stress, for feeding and drinking and for reward) and some neural nodes are shared by more than one core network (Goodson \& Kabelik, 2009).

As the expression of a given behaviour is better reflected by the overall profile of activation of the SBN than by the activity of one of its nodes (Crews et al., 2009; Goodson \& Kabelik, 2009), it is conceivable that different combinations of activation across nodes will be able to produce a wide variation in social behaviour as the weights of each node and of the edges (i.e. connections between nodes) in the network may change at different levels: at the individual level, if node or edge weights change temporally; at the intraspecific level, if weights have a genetic and epigenetic component giving rise to different social phenotypes and at the interspecific level, if weighting is changing with evolution (Goodson \& Kabelik, 2009). Examples of changes in social behaviour paralleled by changes in the dynamic state of the SBN have started to appear in recent years. In the A. carolinensis, repeated exposure to video-playbacks of aggressive displays of conspecific males, that mimic aggressive interactions, led to changes in connectivity within the network (Yang \& Wilczynski, 2007), illustrating how social experience can promote temporal changes in the network functionality within the same individual. In estrildid finches, species differences in sociality are also associated with the differential activation of the different nodes 

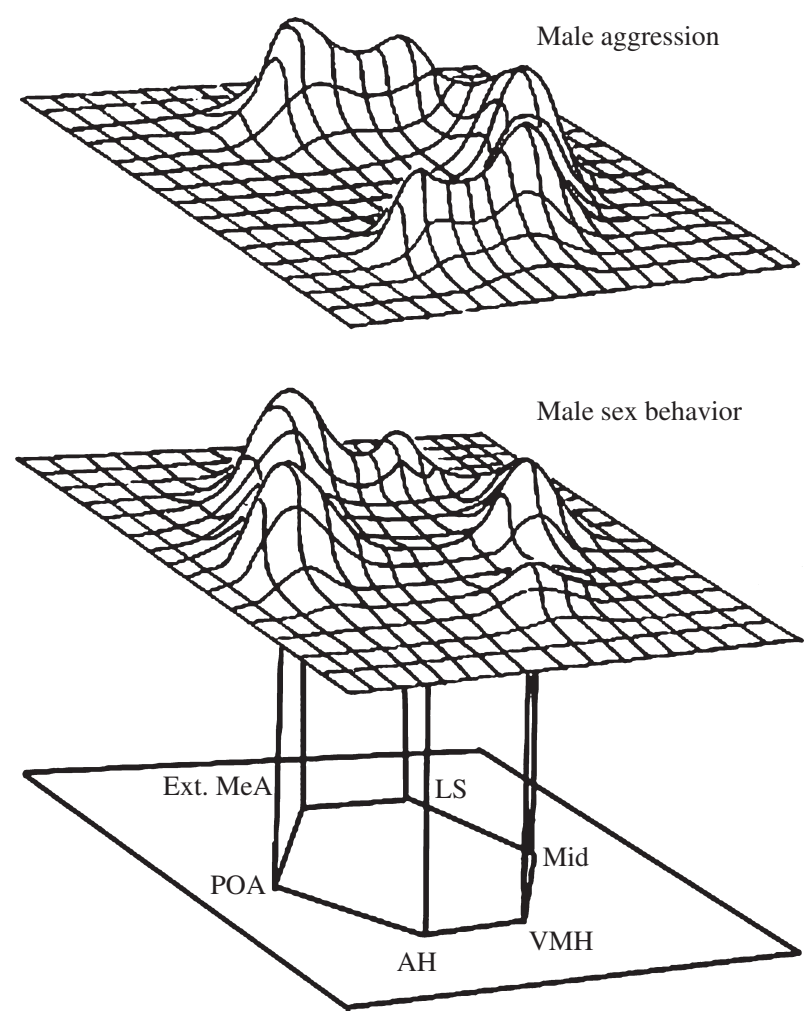

FIG. 2. The social behaviour network is a set of brain areas with reciprocal connections that present different activation states associated with the expression of different social behaviours. Ext. MeA, extended medial amygdala; LS, lateral septum; Mid, central grey in the midbrain; VMH, ventromedial hypothalamus; $\mathrm{AH}$, anterior hypothalamus; POA, preoptic area (adapted with permission from Goodson, 2005).

of the network in response to the presence of a conspecific (Goodson et al., 2005; Fig. 2). Therefore, the study of the patterns of activation across the nodes of the SBN is a promising approach for understanding how the nervous system may generate behavioural diversity at different levels, as the almost limitless of combinations generated is a good base for natural and sexual selection to act on.

Hormone and neuromodulator receptors are expressed in all nodes of the SBN (Goodson, 2005; Caldwell \& Young, 2006; Skuse \& Gallagher, 2009; Munchrath \& Hofmann, 2010), which allows the endocrine and neuromodulatory regulation of the activity of the SBN and also of its connectivity by co-regulated expression of receptors across nodes. As a result, peripheral signals that provide information on the internal state of the animal and general brain state signals conveyed by neuromodulators can be integrated in the processes of social decision-making. Thus, hormones and neuromodulators may regulate the expression of behaviour by acting directly on the pattern of activation of the SBN, or by changing the perceptual inputs it receives or the effector outputs it produces (Oliveira, 2005). The major modulators of the SBN are both sex steroids and neuropeptides from the AVP and OT family that have been shown to have extensive effects on social behaviour (Adkins-Regan, 2005). Hormonal effects on the SBN and consequently on behaviour can occur either at 
the activational or the organizational level (Arnold, 2009), which reflect two major mechanisms of neural plasticity that mediate changes in network patterns of activity and connectivity across different time scales: structural reorganization of the neural circuits and biochemical switching of neural networks (Zupanc \& Lamprecht, 2000). Structural reorganization may be accomplished by different forms of structural modifications that might require adding new cells (neurogenesis) or removing old cells (apoptosis) from the circuit, modifying the connectivity between different components of the network (synaptic plasticity), or changing the responsiveness of the circuit by modifying its molecular components (e.g. differential expression of receptors). Biochemical switching mechanisms allow for a variable response of the same neural network under similar stimulation regimes. This is achieved by different neuroactive molecules (neuromodulators and hormones) that interact with the circuit and alter its functional properties, therefore promoting either excitatory or inhibitory states, and resulting in the occurrence of behaviours adapted to a given context (Kravitz, 2000; Libersat \& Pflüeger, 2004; Huber, 2005; Balthazart \& Ball, 2006). It should also be noted here that constraints and limitations on neural plasticity are also expected. One well-identified trade-off in behavioural decision-making mechanisms is between speed and accuracy, and therefore although neural plasticity allows for increased accuracy, this will limit the speed of social decision-making, especially under noisy conditions (Chittka et al., 2009).

\section{GENOMIC LANDSCAPES FOR SOCIAL PLASTICITY: IMMEDIATE EARLY GENES AND EPIGENOMIC MODIFICATIONS}

Information processing in the central nervous system (CNS) occurs at two different time scales. At the scale of milliseconds, excitatory and inhibitory post-synaptic potentials are integrated by neurons to generate (or not) an action potential. Neuronal integration of information at this level mediates immediate behavioural responses to stimuli. The activity of specific neural circuits in response to particular stimuli is followed by a pulse of gene expression, representing a second, much slower level of neural integration, which occurs within minutes [messenger (m)RNA] to hours (protein) of stimulation (Fig. 1), and that is not directed towards an immediate behavioural response but rather towards the modification of the underlying neural circuitry in an experience-dependent fashion (Clayton, 2000). This genomic response is dependent on the activation of intracellular signalling pathways that respond to extracellular signals and change gene expression in an activity-dependent fashion (e.g. MAPK cascade; Sweatt, 2004; Thomas \& Huganir, 2004). A prominent mechanism that underlies plasticity is the activation of IEG expression by the neuronal activitydependent phosphorylation of CREB, which acts as an IEG transcription factor (Wolf \& Linden, 2012). Therefore, the wave of IEG activation following a stimulus is recruiting temporal correlated associations in neural activity in behavioural significant contexts and promoting the slower alteration of synaptic networks, thereby adjusting the selectivity of long-term information storage and retrieval in neuronal networks (Clayton, 2000; Pinaud \& Tremere, 2006). This is achieved by IEG proteins acting either as direct effectors (e.g. Arc and Homer) that modify synaptic structure and function, or as transcription factors (e.g. c-fos, egr-1, i.e. ngfI-A, zif268, krox24 or zenk) that alter the transcription of other target genes encoding downstream 
effector proteins (e.g. synapsins) (Clayton, 2000; Pinaud \& Tremere, 2006). Thus, temporal and spatial variation in gene expression in the brain regulates the remodelling of neural networks that underlie behavioural plasticity. As IEG expression does not require the activation of any preceding gene and because they modify synaptic structure and function, they represent the earliest genomic response to an inducing stimulus that orchestrates integrated genomic responses to social information. Some IEGs have been shown to be activated within minutes of exposure to specific social cues and to vary their activation with the valence (appetitive $v$. aversive) and salience (e.g. familiarity and complexity) of the social signal (Mello et al., 1992; Jarvis et al., 1998; Dong \& Clayton, 2008). The activation of IEGs has been documented in response to a wide range of social stimuli in different species and sensory modalities (e.g. songbirds: Mello \& Jarvis, 2008; African cichlids: Burmeister \& Fernald, 2005; Burmeister et al., 2005 and frogs: Burmeister et al., 2008), confirming their role as neuromolecular switches for the transduction of social information into changes in brain function and behaviour (Robinson et al., 2008).

In response to IEG expression, co-regulated gene sets (neurogenomic states) are then expected to be co-expressed leading to an association between behaviourally driven gene expression and the expression of social phenotypes. For example, males of an African cichlid Astatotilapia burtoni (Günther 1894) can change social status within minutes if an opportunity occurs. Social ascending males exhibit egr-1 expression in the gonadotropin-releasing hormone $(\mathrm{GnRH})-1$ neurons of the preoptic area that controls the reproductive axis (Burmeister et al., 2005). Dominant and subordinate males are also characterized by different brain transcriptome profiles (Renn et al., 2008), suggesting that rapid and transient IEG responses to social cues can lead to sustained long-term changes in neurogenomic states leading to subsequent structural and physiological changes that characterize social phenotypes (e.g. subordinate $v$. dominant). Thus, social regulation of gene expression in larger gene networks in the brain can be mediated by initial effects of social experience on IEG activation. The stable maintenance of gene expression profiles induced by social experience can be achieved by epigenomic modifications that regulate, in a more-or-less permanent way, the availability of promoter sites to transcription factors, which is accomplished through the physical modification of DNA (e.g. cytosine methylation) or its associated proteins (e.g. histone acetylation). Many epigenomic modifications are acquired during development and are thought to be permanent and life-long (Champagne \& Curley, 2005; Szyf et al., 2008; Curley et al., 2011). There is increasing evidence, however, that these modifications are plastic and that they respond to events in the external environment being involved in synaptic plasticity and memory in the adult brain (Roth \& Sweatt, 2009; Day \& Sweatt, 2011a,b; Nelson \& Monteggia, 2011). In particular, DNA methylation is highly responsive to environmental variations and thus is a good candidate to act as a long-term mediator of phenotypic plasticity (Aubin-Horth \& Renn, 2009). For example, in a recent study, changes in DNA methylation have been characterized in the brains of worker bees Apis mellifera performing differentiated behavioural tasks (nursing $v$. foraging) that illustrate the ability of the neural epigenome to respond to the social environment (Lockett et al., 2012).

The use of high-throughput technologies that make possible measuring the expression of many genes simultaneously, shows that social stimuli induce massive changes (i.e. hundreds to thousands of differentially expressed genes) in gene expression in 
the CNS (Whitfield et al., 2003; Kroes et al., 2006; Cummings et al., 2008; Dong et al., 2009; Sen Sarma et al., 2009; Wurm et al., 2010). This approach has made it clear that social information has broad effects on gene expression and is not restricted to specific genes, and is unravelling how gene regulation underlies social diversity at different levels (e.g. differences in transcriptome profiles between social phenotypes and contexts: hive workers $v$. foragers among A. mellifera; Whitfield et al., 2003: workers $v$. queens among ants Lasius niger; Graff et al., 2007; dominant $v$. subordinate fishes and mammals; Kroes et al., 2006; Renn et al., 2008: monogamous $v$. polygynous African cichlids; Machado et al., 2009: response to social $v$. sexual stimuli; Cummings et al., 2008: territoriality at different life-history stages; Mukai et al., 2009). Differential socially driven changes in transcriptome profile across different brain regions have also been reported and add an extra level of complexity and opportunities for research (e.g. songbirds; Lovell et al., 2008: bee dance; Sen Sarma et al., 2009). All these studies have identified complex network of genes whose expression changes in response to socially relevant information. Gene ontology analysis revealed socially regulated genes involved in a multitude of cellular processes including neuronal plasticity, namely genes from the MAPK signalling cascade that are used to control the cellular responses to external signals across different species (Treisman, 1996) and have been co-opted in mature neurons to function in synaptic plasticity (Sweatt, 2001). The fact that protein kinases are responding to social information is quite relevant for phenotypic plasticity because they mediate phosphorylation changes in other proteins, thereby modifying proteins at a post-translational level, which can lead to the development and maintenance of plastic traits (Aubin-Horth \& Renn, 2009). A clear limitation of the above-mentioned transcriptome studies is that whole brain samples have been used, which potentially masks variation between functional brain areas, and even when using specific brain areas these are made up of different neuronal populations. Thus, there is a need to get more detailed information on specific brain areas of interest and inside these on different neuronal populations to better characterize the genomic make-up of plastic traits. This limitation is particularly relevant for fishes as detailed information (e.g. homologies with mammalian brain areas that request functional information as well as knowledge of connection patterns between areas) on specific brain areas is still incomplete or missing for most species (Wullimann \& Mueller, 2004; Nieuwenhuys, 2009).

\section{EVOLUTIONARY AND ECOLOGICAL LANDSCAPES FOR SOCIAL PLASTICITY: ORGANISMAL PERFORMANCE TRAITS AND PHENOTYPIC PLASTICITY}

The 'performance paradigm', originally proposed by Arnold (1983), assumes that the variation in the ability of organisms to perform ecologically relevant tasks (performance traits), such as sprint speed, biting force or capacity for endurance, emerges from variation in underlying morphological and physiological traits (lower level traits). On the other hand, as organisms interact with the environment through their functional capacities, natural selection is expected to operate primarily on performance traits and only indirectly on lower level traits (Arnold, 1983; Irschick \& Garland, 2001; Lailvaux \& Irschick, 2006). Hence, alleles with pleiotropic effects 
that facilitate the co-ordinated evolution of components of performance traits are expected to be favoured, and the genetic architecture of the subordinate traits involved is expected to evolve to become more consistent with the prevailing patterns of multivariate selection, leading to further evolution and adaptive radiation (Garland \& Kelly, 2006). Therefore, performance should be correlated with the Darwinian fitness of the organism (Irschick et al., 2008).

One key performance trait is the ability of the organism to change its phenotype in response to changes in the environment by re-programming the genome (i.e. phenotypic plasticity; Pigliucci, 2001; West-Eberhard, 2003). The characterization of the change in a genotype's phenotype across an environmental gradient (reaction norm), has unravelled interindividual differences in the degree of plasticity that rely on genetic variation (Pigliucci, 2005). Hence, phenotypic plasticity can evolve within limits imposed by costs and constraints to plasticity (DeWitt et al., 1998), if fitness is increased by the changing phenotype. The possibility that selection acts on variation in plasticity, however, has received little attention to date (Pigliucci, 2005; Nussey et al., 2007). On the other hand, despite the considerable attention that phenotypic plasticity has received on evolutionary biology, the emphasis has been on permanent environmental effects on morphological and life-history traits during the development of the phenotype rather than on labile plastic traits in the adult life of the organism, such as behaviour (Pigliucci, 2005; Nussey et al., 2007).

At the behavioural level, the social domain, owing to its high variability, is expected to be a major selective force for the evolution of behavioural flexibility. It is important to note here that plasticity is only favoured in predictable variable environments where there are reliable cues available to predict the future state of the environment, but not in stochastic environments where bet-hedging strategies are expected (Olofsson et al., 2009; Simons, 2011). Animals vary both in the average level of expression of behavioural traits (i.e. personality) and in the responsiveness to social stimuli (plasticity). These two contrasting dimensions, individual behavioural consistency and plasticity, were often approached separately by evolutionary biologists but it is now evident that these aspects are complementary and should be studied simultaneously (Dingemanse et al., 2010; Wolf et al., 2011). Within-species variation in social plasticity has important evolutionary consequences and evolutionary models that integrate individual consistency and plasticity in order to explain the occurrence of behavioural profiles and variance in behavioural plasticity within populations have now been put forward (Wolf et al., 2008). In socially more complex and dynamic environments, selection may act to promote more plastic phenotypes, while in more stable environments selection may favour particular values of the behavioural responses when the costs of maintaining flexibility are high.

A conceptual framework for the study of phenotypic behavioural plasticity based on the notion of behavioural reaction norms has been recently proposed (Dingemanse et al., 2010). In this approach, the trait of interest for evolution is the behavioural reaction norm itself, i.e. the shape of the behavioural response over an environmental gradient and not the average value of the behaviour (Dingemanse et al., 2010). The behavioural response to the environmental gradient integrates both individual behavioural consistency (personality) and plasticity (Conrad et al., 2011). Assuming a linear relationship between behaviour and environmental cues, differences in the intercept (elevation) of the fitted regression line represents average differences in behaviour (personality) while different slopes represent variation in behavioural 


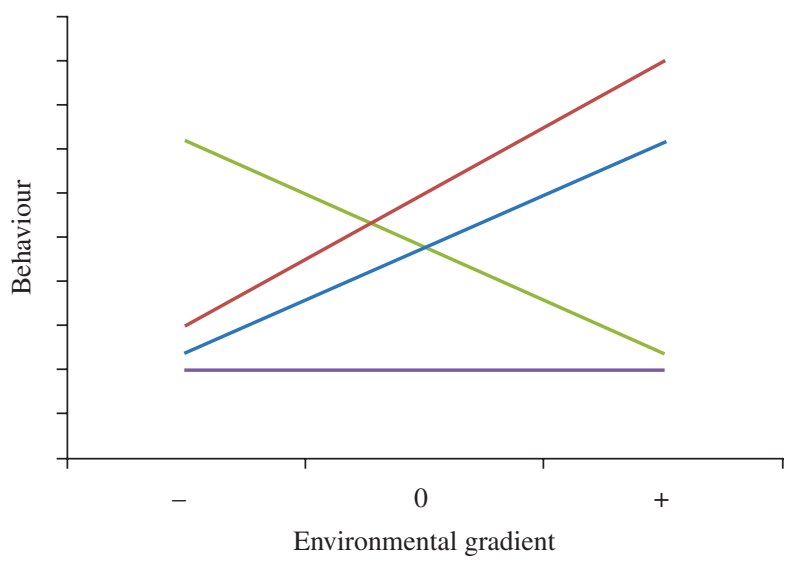

FIG. 3. Hypothetical linear behavioural reaction norms of four different subjects to the same environmental gradient. An example could be the variation in the frequency of aggressive behaviours with social group size. While some animals do not respond to group size increase (subject 4), others increase (subjects 1 and 2) or decrease (subject 3) the frequency of the behaviour. Differences in slopes represent differences in behavioural plasticity. For instance, subjects 1, 2 and 3 are more plastic than subject 4 . Differences in the trait mean represent different behavioural profiles. For example, subjects 1, 2 and 3 are, on average, more aggressive than subject $4 . \ldots_{\text {, }}$ subject $1 ; \ldots$, subject $2 ; \ldots$, subject $3 ; \ldots$, subject 4 .

plasticity (Fig. 3). Interestingly, certain behavioural types (i.e. personalities) are inherently characterized to be more plastic (e.g. differences in routine formation and learning between proactiveand reactive coping styles in rodents and fishes; Koolhas et al., 1999; Øverli et al., 2004, 2007), which can be due, for example, to a ceiling effect (e.g. bold-aggressive animals are less plastic than shy non-aggressive ones) on the plasticity of their boldness or aggression as they are already closer to the trait maximum and therefore have a lower scope for response (Sih et al., 2004; Sih \& Bell, 2008). Importantly, because animals with more plastic behavioural responses in one dimension have been reported to be more plastic in other dimensions (Benus et al., 1990; Branchi, 2009; Curley et al., 2009; Arnold \& Taborsky, 2010; Taborsky et al., 2012), molecular mechanisms favouring general behavioural plasticity are predicted. Under the present conceptual framework, interindividual variation in social plasticity would result from variation in the ability to alternate between neurogenomic states in the nodes of the SBN. If this variation has an additive genetic component, social plasticity can be the target of natural selection.

According to the theoretical framework proposed here, intra-individual variation in social plasticity on which selection acts is the outcome of variation in the plasticity of the neurogenomic states that underlie the expression of alternative behavioural states. In that sense, genetic variation affecting the evolution of social plasticity may come: (1) from variation in the coding sequence of structural genes expressed in the gene modules associated with each phenotypic state or (2) from variation in the sequence of regulatory regions (i.e. cis-regulatory elements and transcription factors). Interestingly, evidence has been accumulating showing that phenotypic (both morphologic and behavioural) diversification is more dependent on the pleiotropic effects of small regulatory regions than on structural gene modification (Wagner, 
2000; Levine \& Tjian, 2003; Jovelin et al., 2009; Wolf et al., 2010). Likewise, regulatory elements are probably fundamental players in orchestrating the switch between gene modules associated with different behaviours, and thus regulatory regions constitute primary candidates for investigating the targets of selection driving phenotypic behavioural diversity.

\section{CONCLUDING REMARKS}

The integrative framework for the study of social plasticity presented here is expected to unravel how knowledge of the proximate mechanisms underlying social plasticity is crucial to understanding the costs, limits and evolutionary consequences of social plasticity, thereby highlighting the fact that proximate mechanisms contribute to the dynamics of selection.

The great diversity of social behaviour among fishes that may occur both within and between species and its high plasticity within the same individual place fishes in an outstanding position for the comparative and integrative study of social plasticity. In the near future, careful experimental designs using the right species will certainly allow timely questions in the field to be addressed such as: how do animals perceive social information and how is it translated into a genomic response in the brain? How do perceived changes in social environment trigger adaptive changes in behaviour through changes in gene expression in neural networks underlying social behaviour? Does social plasticity have an additive genetic variation component that allows for its selection?

In a more conceptual view, the integrative framework to social plasticity presented here will provide a comprehensive case study to illustrate how reciprocal causation analysis of biological phenomena (i.e. considering the interaction between immediate factors and evolutionary explanations) can be a more useful approach than the traditional proximate-ultimate dichotomy, according to which evolutionary processes can be understood without understanding proximate causes (i.e. black-boxing development and physiology).

I thank David Gonçalves as well as all present and past laboratory members for stimulating discussions on this topic that certainly helped to shape some of the ideas exposed here as well as the three anonymous referees who contributed to the improvement of the final manuscript. The writing of this paper was supported by the following grants from Fundação paa a Ciência e a Tecnologia: PTDC/MAR/72117/2006 and RG-LVT-331-2352.

\section{References}

Adkins-Regan, E. (2005). Hormones and Animal Social Behavior. Princeton, NJ: Princeton University Press.

Ahrens, M. B., Li, J. M., Orger, M. B., Robson, D. N., Schier, A. F., Engert, F. \& Portugues, R. (2012). Brain-wide neuronal dynamics during motor adaptation in zebrafish. Nature 485, 471-477.

Aires, R. F., Ros, A. F. H., Oliveira, T. \& Oliveira, R. F. (2004). Androgens and the dear enemy effect in a cichlid fish. Hormones and Behavior 46, 106.

Arai, T., Tominaga, O., Seikai, T. \& Masuda, R. (2007). Observational learning improves predator avoidance in hatchery-reared Japanese flounder Paralichthys olivaceus juveniles. Journal of Sea Research 58, 59-64. 
Arnold, S. J. (1983). Sexual selection: the interface of theory and empiricism. In Mate Choice (Bateson, P., ed.), pp. 67-107. Cambridge: Cambridge University Press.

Arnold, A. P. (2009). The organizational-activational hypothesis as the foundation for a unified theory of sexual differentiation of all mammalian tissues. Hormones and Behavior 55, 570-578.

Arnold, C. \& Taborsky, B. (2010). Social experience in early ontogeny has lasting effects on social skills in cooperatively breeding cichlids. Animal Behaviour 79, 621-630.

Aubin-Horth, N. \& Renn, S. C. (2009). Genomic reaction norms: using integrative biology to understand molecular mechanisms of phenotypic plasticity. Molecular Ecology 18, $3763-3780$.

Balthazart, J. \& Ball, G. F. (2006). Is brain estradiol a hormone or a neurotransmitter? Trends in Neurosciences 29, 241-249.

Benus, R. F., Dendaas, S., Koolhaas, J. M. \& Vanoortmerssen, G. A. (1990). Routine formation and flexibility in social and nonsocial behavior of aggressive and nonaggressive male-mice. Behaviour 112, 176-193.

Branchi, I. (2009). The mouse communal nest: investigating the epigenetic influences of the early social environment on brain and behavior development. Neuroscience and Biobehavioral Reviews 33, 551-559.

Broglio, C., Gomez, A., Duran, E., Ocana, F. M., Jimenez-Moya, F., Rodriguez, F. \& Salas, C. (2005). Hallmarks of a common forebrain vertebrate plan: specialized pallial areas for spatial, temporal and emotional memory in actinopterygian fish. Brain Research Bulletin 66, 277-281.

Brown, C. \& Laland, K. (2011). Social learning in fishes. In Fish Cognition and Behavior (Brown, C., Laland, K. \& Krause, J., eds), pp. 240-257. Oxford: Wiley-Blackwell.

Bshary, R. (2011). Machiavellian intelligence in fishes. In Fish Cognition and Behavior (Brown, C., Laland, K. \& Krause, J., eds), pp. 277-297. Oxford: Wiley-Blackwell.

Bshary, R., Wickler, W. \& Fricke, H. (2002). Fish cognition: a primate's eye view. Animal Cognition 5, 1-13.

Burke, C. J., Tobler, P. N., Baddeley, M. \& Schultz, W. (2010). Neural mechanisms of observational learning. Proceedings of the National Academy of Sciences of the United States of America 107, 14431-14436.

Burmeister, S. S. \& Fernald, R. D. (2005). Evolutionary conservation of the Egr-1 immediateearly gene response in a teleost. Journal of Comparative Neurology 481, 220-232.

Burmeister, S. S., Jarvis, E. D. \& Fernald, R. D. (2005). Rapid behavioral and genomic responses to social opportunity. PLoS Biology 3, e363.

Burmeister, S. S., Mangiamele, L. A. \& Lebonville, C. L. (2008). Acoustic modulation of immediate early gene expression in the auditory midbrain of female tungara frogs. Brain Research 1190, 105-114.

Burns, J. G., Foucaud, J. \& Mery, F. (2011). Costs of memory: lessons from 'mini' brains. Proceedings of the Royal Society B 278, 923-929.

Caldwell, H. K. \& Young, W. S. (2006). Oxytocin and Vasopressin: Genetics and Behavioral Implications. Berlin: Springer-Verlag.

Champagne, F. A. \& Curley, J. P. (2005). How social experiences influence the brain. Current Opinion in Neurobiology 15, 704-709.

Chittka, L., Skorupski, P. \& Raine, N. E. (2009). Speed-accuracy tradeoffs in animal decision making. Trends in Ecology and Evolution 24, 400-407.

Clayton, D. F. (2000). The genomic action potential. Neurobiology of Learning and Memory 74, $185-216$.

Conrad, J. L., Weinersmith, K. L., Brodin, T., Saltz, J. B. \& Sih, A. (2011). Behavioural syndromes in fishes: a review with implications for ecology and fisheries management. Journal of Fish Biology 78, 395-435.

Crews, D., Rushworth, D., Gonzalez-Lima, F. \& Ogawa, S. (2009). Litter environment affects behavior and brain metabolic activity of adult knockout mice. Frontiers in Behavioral Neuroscience 3, 12.

Cummings, M. E., Larkins-Ford, J., Reilly, C. R. L., Wong, R. Y., Ramsey, M. \& Hofmann, H. A. (2008). Sexual and social stimuli elicit rapid and contrasting genomic responses. Proceedings of the Royal Society B 275, 393-402. 
Curley, J. P., Davidson, S., Bateson, P. \& Champagne, F. A. (2009). Social enrichment during postnatal development induces transgenerational effects on emotional and reproductive behavior in mice. Frontiers in Behavioral Neuroscience 3, 25.

Curley, J. P., Jensen, C. L., Mashoodh, R. \& Champagne, F. A. (2011). Social influences on neurobiology and behavior: epigenetic effects during development. Psychoneuroendocrinology 36, 352-371.

Day, J. J. \& Sweatt, J. D. (2011a). Cognitive neuroepigenetics: a role for epigenetic mechanisms in learning and memory. Neurobiology of Learning and Memory 96, 2-12.

Day, J. J. \& Sweatt, J. D. (2011b). Epigenetic mechanisms in cognition. Neuron 70, 813-829.

Desjardins, J. K. \& Fernald, R. D. (2009). Fish sex: why so diverse? Current Opinion in Neurobiology 19, 648-653.

Desjardins, J. K. \& Fernald, R. D. (2010). What do fish make of mirror images? Biology Letters 6, 744-747.

DeWitt, T. J., Sih, A. \& Wilson, D. S. (1998). Costs and limits of phenotypic plasticity. Trends in Ecology and Evolution 13, 77-81.

Dijkstra, P. D., Schaafsma, S. M., Hofmann, H. A. \& Groothuis, T. G. (2012). 'Winner effect' without winning: unresolved social conflicts increase the probability of winning a subsequent contest in a cichlid fish. Physiology and Behavior 105, 489-492.

Dingemanse, N. J., Kazem, A. J. N., Réale, D. \& Wright, J. (2010). Behavioural reaction norms: animal personality meets individual plasticity. Trends in Ecology and Evolution 25, 81-89.

Dingemanse, N. J., Barber, I., Wright, J. \& Brommer, J. E. (2012). Quantitative genetics of behavioural reaction norms: genetic correlations between personality and behavioural plasticity vary across stickleback populations. Journal of Evolutionary Biology 25, $485-496$.

Dong, S. \& Clayton, D. F. (2008). Partial dissociation of molecular and behavioral measures of song habituation in adult zebra finches. Genes Brain and Behavior 7, 802-809.

Dong, S., Replogle, K. L., Hasadsri, L., Imai, B. S., Yau, P. M., Rodriguez-Zas, S., Southey, B. R., Sweedler, J. V. \& Clayton, D. F. (2009). Discrete molecular states in the brain accompany changing responses to a vocal signal. Proceedings of the National Academy of Sciences of the United States of America 106, 11364-11369.

Dukas, R. (1999). Costs of memory: ideas and predictions. Journal of Theoretical Biology 197, 41-50.

Dunbar, R. I. \& Shultz, S. (2007). Evolution in the social brain. Science 317, 1344-1347.

Dzieweczynski, T. L., Eklund, A. C. \& Rowland, W. J. (2006). Male 11-ketotestosterone levels change as a result of being watched in Siamese fighting fish, Betta splendens. General and Comparative Endocrinology 147, 184-189.

Galef, B. G. Jr. \& Laland, K. N. (2005). Social learning in animals: empirical studies and theoretical models. BioScience 55, 489-499.

Galhardo, L., Vital, J. \& Oliveira, R. F. (2011). The role of predictability in the stress response of a cichlid fish. Physiology and Behavior 102, 367-372.

Garland, T. Jr. \& Kelly, S. A. (2006). Phenotypic plasticity and experimental evolution. Journal of Experimental Biology 209, 2344-2361.

Godwin, J. (2010). Neuroendocrinology of sexual plasticity in teleost fishes. Frontiers in Neuroendocrinology 31, 203-216.

Goodson, J. L. (2005). The vertebrate social behavior network: evolutionary themes and variations. Hormones and Behavior 48, 11-22.

Goodson, J. L. \& Kabelik, D. (2009). Dynamic limbic networks and social diversity in vertebrates: from neural context to neuromodulatory patterning. Frontiers in Neuroendocrinology 30, 429-441.

Goodson, J. L., Evans, A. K., Lindberg, L. \& Allen, C. D. (2005). Neuro-evolutionary patterning of sociality. Proceedings of the Royal Society B 272, 227-235.

Graff, J., Jemielity, S., Parker, J. D., Parker, K. M. \& Keller, L. (2007). Differential gene expression between adult queens and workers in the ant Lasius niger. Molecular Ecology 16, 675-683.

Grosenick, L., Clement, T. S. \& Fernald, R. D. (2007). Fish can infer social rank by observation alone. Nature 445, 429-432. 
Heyes, C. M. (1994). Social-learning in animals: categories and mechanisms. Biological Reviews of the Cambridge Philosophical Society 69, 207-231.

Hirschenhauser, K., Wittek, M., Johnston, P. \& Mostl, E. (2008). Social context rather than behavioral output or winning modulates post-conflict testosterone responses in Japanese quail (Coturnix japonica). Physiology and Behavior 95, 457-463.

Hsu, Y., Earley, R. L. \& Wolf, L. L. (2006). Modulation of aggressive behaviour by fighting experience: mechanisms and contest outcomes. Biological Reviews of the Cambridge Philosophical Society 81, 33-74.

Huber, R. (2005). Amines and motivated behaviors: a simpler systems approach to complex behavioral phenomena. Journal of Comparative Physiology A 191, 231-239.

Irschick, D. J. \& Garland, T. Jr. (2001). Integrating function and ecology in studies of adaptation: investigations of locomotor capacity as a model system. Annual Review of Ecology and Systematics 32, 367-396.

Irschick, D. J., Meyers, J. J., Husak, J. F. \& Le Galliard, J. (2008). How does selection operate on whole-organism functional performance capacities? A review and synthesis. Evolutionary Ecology Research 10, 177-196.

Jarvis, E. D., Scharff, C., Grossman, M. R., Ramos, J. A. \& Nottebohm, F. (1998). For whom the bird sings: context-dependent gene expression. Neuron 21, 775-788.

Jovelin, R., Dunham, J. P., Sung, F. S. \& Phillips, P. C. (2009). High nucleotide divergence in developmental regulatory genes contrasts with the structural elements of olfactory pathways in Caenorhabditis. Genetics 181, 1387-1397.

Kappeler, P. \& Kraus, C. (2010). Levels and mechanisms of behavioural variability. In Animal Behaviour: Evolution and Mechanisms (Kappeler, P. M., ed.), pp. 655-684. Heidelberg: Springer-Verlag.

Kelley, A. E. \& Berridge, K. C. (2002). The neuroscience of natural rewards: relevance to addictive drugs. Journal of Neuroscience 22, 3306-3311.

Kendal, R. L., Coolen, I. \& Laland, K. N. (2009). Adaptive trade-offs in the use of social and personal information. In Cognitive Ecology II (Dukas, R. \& Ratcliffe, J. M., eds), pp. 249-271. Chicago, IL: University of Chicago Press.

Koolhas, J. M., Korte, S. M., De Boer, S. F., Van Der Vegt, B. J., Van Reenen, C. G., Hopsterb, H., De Jong, I. C., Ruis, M. A. W. \& Blokhuis, H. J. (1999). Coping styles in animals: current status in behavior and stress-physiology. Neuroscience and Biobehavioral Reviews 23, 925-935.

Kornfield, I. \& Smith, P. F. (2000). African cichlid fishes: model systems for evolutionary biology. Annual Review of Ecology and Systematics 31, 163-196.

Korzan, W. J., Summers, T. R., Ronan, P. J. \& Summers, C. H. (2000a). Visible sympathetic activity as a social signal in Anolis carolinensis: changes in aggression and plasma catecholamines. Hormones and Behavior 38, 193-199.

Korzan, W. J., Summers, T. R. \& Summers, C. H. (2000b). Monoaminergic activities of limbic regions are elevated during aggression: influence of sympathetic social signaling. Brain Research 870, 170-178.

Korzan, W. J., Summers, T. R., Ronan, P. J., Renner, K. J. \& Summers, C. H. (2001). The role of monoaminergic nuclei during aggression and sympathetic social signaling. Brain Behavior and Evolution 57, 317-327.

Kravitz, E. A. (2000). Serotonin and aggression: insights gained from a lobster model system and speculations on the role of amine neurons in a complex behavior. Journal of Comparative Physiology A 186, 221-238.

Krebs, H. A. (1975). The August Krogh Principle:"For many problems there is an animal on which it can be most conveniently studied". Journal of Experimental Zoology 194, 221-226.

Kroes, R. A., Panksepp, J., Burgdorf, J., Otto, N. J. \& Moskal, J. R. (2006). Modeling depression: social dominance-submission gene expression patterns in rat neocortex. Neuroscience 137, 37-49.

Krogh, A. (1929). Progress of physiology. American Journal of Physiology 90, 243-251.

Lailvaux, S. P. \& Irschick, D. J. (2006). A functional perspective on sexual selection: insights and future prospects. Animal Behaviour 72, 263-273.

Laland, K. N. (2004). Social learning strategies. Learning and Behavior 32, 4-14. 
Lazarus, R. S. (1991). Cognition and motivation in emotion. American Psychologist 46, 352-367.

Levine, M. \& Tjian, R. (2003). Transcription regulation and animal diversity. Nature 424, $147-151$.

Libersat, F. \& Pflüeger, H.-J. (2004). Monoamines and the orchestration of behavior. BioScience 54, 17-25.

Lockett, G. A., Kucharski, R. \& Maleszka, R. (2012). DNA methylation changes elicited by social stimuli in the brains of worker honey bees. Genes, Brain and Behavior 11, $235-242$.

Lohr, H., Ryu, S. \& Driever, W. (2009). Zebrafish diencephalic A11-related dopaminergic neurons share a conserved transcriptional network with neuroendocrine cell lineages. Development 136, 1007-1017.

Lovell, P. V., Clayton, D. F., Replogle, K. L. \& Mello, C. V. (2008). Birdsong "transcriptomics": neurochemical specializations of the oscine song system. PLoS One 3, e3440.

Machado, H. E., Pollen, A. A., Hofmann, H. A. \& Renn, S. C. (2009). Interspecific profiling of gene expression informed by comparative genomic hybridization: a review and a novel approach in African cichlid fishes. Integrative and Comparative Biology 49, $644-659$.

McEwen, B. S. (1991). Non-genomic and genomic effects of steroids on neural activity. Trends in Pharmacological Sciences 12, 141-147.

McNamara, J. M. \& Houston, A. I. (2009). Integrating function and mechanism. Trends in Ecology and Evolution 24, 670-675.

Mello, C. V. \& Jarvis, E. D. (2008). Behavior-dependent expression of inducible genes invocal learning birds. In Neuroscience of Bird Song (Zeigler, H. P. \& Marler, P., eds), pp. 381-397. Cambridge: Cambridge University Press.

Mello, C. V., Vicario, D. S. \& Clayton, D. F. (1992). Song presentation induces gene expression in the songbird forebrain. Proceedings of the National Academy of Sciences of the United States of America 89, 6818-6822.

Mendl, M., Burman, O. H. \& Paul, E. S. (2010). An integrative and functional framework for the study of animal emotion and mood. Proceedings of the Royal Society B 277, 2895-2904.

Meyer, A. \& Van de Peer, Y. (2005). From 2R to 3R: evidence for a fish-specific genome duplication (FSGD). Bioessays 27, 937-945.

Moore, F. L. \& Evans, S. J. (1999). Steroid hormones use non-genomic mechanisms to control brain functions and behaviors: a review of evidence. Brain Behavior and Evolution 54, 41-50.

Mukai, M., Replogle, K., Drnevich, J., Wang, G., Wacker, D., Band, M., Clayton, D. F. \& Wingfield, J. C. (2009). Seasonal differences of gene expression profiles in song sparrow (Melospiza melodia) hypothalamus in relation to territorial aggression. PLoS One 4, e8182.

Munchrath, L. A. \& Hofmann, H. A. (2010). Distribution of sex steroid hormone receptors in the brain of an African cichlid fish, Astatotilapia burtoni. Journal of Comparative Neurology 518, 3302-3326.

Muto, A. \& Kawakami, K. (2011). Imaging functional neural circuits in zebrafish with a new GCaMP and the Gal4FF-UAS system. Communicative and Integrative Biology 4, $566-568$.

Nelson, E. D. \& Monteggia, L. M. (2011). Epigenetics in the mature mammalian brain: effects on behavior and synaptic transmission. Neurobiology of Learning and Memory 96, 53-60.

Newman, S. W. (1999). The medial extended amygdala in male reproductive behavior a node in the mammalian social behavior network. Annals of the New York Academy of Sciences 877, $242-257$.

Nieuwenhuys, R. (2009). The forebrain of actinopterygians revisited. Brain Behavior and Evolution 73, 229-252.

Nussey, D. H., Wilson, A. J. \& Brommer, J. E. (2007). The evolutionary ecology of individual phenotypic plasticity in wild populations. Journal of Evolutionary Biology 20, $831-844$. 
O'Connell, L. A. \& Hofmann, H. A. (2011). The vertebrate mesolimbic reward system and social behavior network: a comparative synthesis. Journal of Comparative Neurology 519, 3599-3639.

O'Connell, L. A. \& Hofmann, H. A. (2012). Evolution of a vertebrate social decision-making network. Science 336, 1154-1157.

Oliveira, R. F. (2005). Hormones, social context and animal communication. In Animal Communication Networks (McGregor, P. K., ed.), pp. 481-520. Cambridge: Cambridge University Press.

Oliveira, R. F. (2009). Social behavior in context: hormonal modulation of behavioral plasticity and social competence. Integrative and Comparative Biology 49, 423-440.

Oliveira, R. F. \& Canario, A. V. (2011). Nemo through the looking-glass: a commentary on Desjardins \& Fernald. Biology Letters 7, 487-488.

Oliveira, R. F., Lopes, M., Carneiro, L. A. \& Canario, A. V. (2001). Watching fights raises fish hormone levels. Nature 409, 475.

Oliveira, R. F., Ros, A. F. H. \& Goncalves, D. M. (2005a). Intra-sexual variation in male reproduction in teleost fish: a comparative approach. Hormones and Behavior 48, 430-439.

Oliveira, R. F., Carneiro, L. A. \& Canario, A. V. (2005b). No hormonal response in tied fights. Nature 437, 207-208.

Oliveira, R. F., Silva, A. \& Canario, A. V. (2009). Why do winners keep winning? Androgen mediation of winner but not loser effects in cichlid fish. Proceedings of the Royal Society B 276, 2249-2256.

Olofsson, H., Ripa, J. \& Jonzen, N. (2009). Bet-hedging as an evolutionary game: the tradeoff between egg size and number. Proceedings of the Royal Society B 276, 2963-2969.

Øverli, Ø., Korzan, W. J., Larson, E. T., Winberg, S., Lepage, O., Pottinger, T. G., Renner, K. J. \& Summers, C. H. (2004). Behavioral and neuroendocrine correlates of displaced aggression in trout. Hormones and Behavior 45, 324-329.

Øverli, Ø., Sørensen, C., Pulman, K. G. T., Pottinger, T. G., Korzan, W., Summers, C. H. \& Nilsson, G. E. (2007). Evolutionary background for stress-coping styles: relationships between physiological, behavioral, and cognitive traits in non-mammalian vertebrates. Neuroscience and Biobehavioral Reviews 31, 396-412.

Paul, E. S., Harding, E. J. \& Mendl, M. (2005). Measuring emotional processes in animals: the utility of a cognitive approach. Neuroscience and Biobehavioral Reviews 29, 469-491.

Peake, T. M. \& McGregor, P. K. (2004). Information and aggression in fishes. Learning and Behavior 32, 114-121.

Penn, J. K. M., Zito, M. F. \& Kravitz, E. A. (2010). A single social defeat reduces aggression in a highly aggressive strain of Drosophila. Proceedings of the National Academy of Sciences of the United States of America 107, 12682-12686.

Piersma, T. \& Drent, J. (2003). Phenotypic flexibility and the evolution of organismal design. Trends in Ecology and Evolution 18, 228-233.

Pigliucci, M. (2001). Phenotypic Plasticity: Beyond Nature and Nurture. Baltimore, MD: John Hopkins University Press.

Pigliucci, M. (2005). Evolution of phenotypic plasticity: where are we going now? Trends in Ecology and Evolution 20, 481-486.

Pigliucci, M. \& Hayden, K. (2001). Phenotypic plasticity is the major determinant of changes in phenotypic integration in Arabidopsis. New Phytologist 152, 419-430.

Pinaud, R. \& Tremere, L. A. (2006). Immediate Early Genes in Sensory Processing, Cognitive Performance and Neurological Disorders. New York, NY: Springer.

Price, T. D., Qvarnström, A. \& Irwin, D. E. (2003). The role of phenotypic plasticity in driving genetic evolution. Proceedings of the Royal Society B 270, 1433.

Renn, S. C., Aubin-Horth, N. \& Hofmann, H. A. (2008). Fish and chips: functional genomics of social plasticity in an African cichlid fish. Journal of Experimental Biology 211, 3041-3056.

Rink, E. \& Wullimann, M. F. (2001). The teleostean (zebrafish) dopaminergic system ascending to the subpallium (striatum) is located in the basal diencephalon (posterior tuberculum). Brain Research 889, 316-330. 
Rink, E. \& Wullimann, M. F. (2002). Connections of the ventral telencephalon and tyrosine hydroxylase distribution in the zebrafish brain (Danio rerio) lead to identification of an ascending dopaminergic system in a teleost. Brain Research Bulletin 57, 385-387.

Robinson, G. E., Fernald, R. D. \& Clayton, D. F. (2008). Genes and social behavior. Science 322, 896-900.

Roth, T. L. \& Sweatt, J. D. (2009). Regulation of chromatin structure in memory formation. Current Opinion in Neurobiology 19, 336-342.

Rowland, W. J. (1999). Studying visual cues in fish behavior: a review of ethological techniques. Environmental Biology of Fishes 56, 285-305.

Rutte, C., Taborsky, M. \& Brinkhof, M. W. (2006). What sets the odds of winning and losing? Trends in Ecology and Evolution 21, 16-21.

Scherer, K. R. (2001). Appraisal considered as a process of multi-level sequential checking. In Appraisal Processes in Emotion: Theory, Methods, Research (Scherer, K. R. \& Johnstone, T., eds), pp. 92-120. Oxford: Oxford University Press.

Sen Sarma, M., Rodriguez-Zas, S. L., Hong, F., Zhong, S. \& Robinson, G. E. (2009). Transcriptomic profiling of central nervous system regions in three species of honey bee during dance communication behavior. PLoS One 4, e6408.

Sih, A. \& Bell, A. M. (2008). Insights for behavioral ecology from behavioral syndromes. Advances in the Study of Behavior 38, 227-281.

Sih, A., Bell, A. M., Johnson, J. C. \& Ziemba, R. E. (2004). Behavioral syndromes: an integrative overview. Quarterly Review of Biology 79, 241-277.

Simons, A. M. (2011). Modes of response to environmental change and the elusive empirical evidence for bet hedging. Proceedings of the Royal Society B 278, 1601-1609.

Skuse, D. H. \& Gallagher, L. (2009). Dopaminergic-neuropeptide interactions in the social brain. Trends in Cognitive Sciences 13, 27-35.

Smeets, W. J. A. J., Marin, O. \& Gonzalez, A. (2000). Evolution of the basal ganglia: new perspectives through a comparative approach. Journal of Anatomy 196, 501-517.

Smiseth, P. T., Wright, J. \& Kölliker, M. (2008). Parent-offspring conflict and co-adaptation: behavioural ecology meets quantitative genetics. Proceedings of the Royal Society $B$ 275, $1823-1830$.

Striedter, G. F. \& Northcutt, R. G. (2006). Head size constrains forebrain development and evolution in ray-finned fishes. Evolution and Development 8, 215-222.

Swaney, W., Kendal, J., Capon, H., Brown, C. \& Laland, K. N. (2001). Familiarity facilitates social learning of foraging behaviour in the guppy. Animal Behaviour 62, 591-598.

Sweatt, J. D. (2001). The neuronal MAP kinase cascade: a biochemical signal integration system subserving synaptic plasticity and memory. Journal of Neurochemistry 76, 1-10.

Sweatt, J. D. (2004). Mitogen-activated protein kinases in synaptic plasticity and memory. Current Opinion in Neurobiology 14, 311-317.

Szyf, M., McGowan, P. \& Meaney, M. J. (2008). The social environment and the epigenome. Environmental and Molecular Mutagenesis 49, 46-60.

Taborsky, M. (2008). Alternative reproductive tactics in fish. In Alternative Reproductive Tactics: An Integrative Approach (Oliveira, R. F., Taborsky, M. \& Brockmann, H. J., eds), pp. 251-299. Cambridge: Cambridge University Press.

Taborsky, B., Arnold, C., Junker, J. \& Tschopp, A. (2012). The early social environment affects social competence in a cooperative breeder. Animal Behaviour 83, 1067-1074.

Tay, T. L., Ronneberger, O., Ryu, S., Nitschke, R. \& Driever, W. (2011). Comprehensive catecholaminergic projectome analysis reveals single-neuron integration of zebrafish ascending and descending dopaminergic systems. Nature Communications 2, 171.

Thomas, G. M. \& Huganir, R. L. (2004). MAPK cascade signalling and synaptic plasticity. Nature Reviews in Neuroscience 5, 173-183.

Treisman, R. (1996). Regulation of transcription by MAP kinase cascades. Current Opinion in Cell Biology 8, 205-215.

Van der Linden, A., Verhoye, M., Portner, H. O. \& Bock, C. (2004). The strengths of in vivo magnetic resonance imaging (MRI) to study environmental adaptational physiology in fish. Magnetic Resonance Materials in Physics, Biology and Medicine 17, 236-248.

Wagner, A. (2000). Decoupled evolution of coding region and mRNA expression patterns after gene duplication: implications for the neutralist-selectionist debate. Proceedings of the National Academy of Sciences of the United States of America 97, 6579-6584. 
Wang, Z., Gerstein, M. \& Snyder, M. (2009). RNA-Seq: a revolutionary tool for transcriptomics. Nature Reviews Genetics 10, 57-63.

West-Eberhard, M. J. (1989). Phenotypic plasticity and the origins of diversity. Annual Review of Ecology and Systematics 20, 249-278.

West-Eberhard, M. J. (2003). Developmental Plasticity And Evolution: New York, NY: Oxford University Press, Inc.

Westneat, D. F., Hatch, M. I., Wetzel, D. P. \& Ensminger, A. L. (2011). Individual variation in parental care reaction norms: integration of personality and plasticity. American Naturalist 178, 652-667.

Whitfield, C. W., Cziko, A. M. \& Robinson, G. E. (2003). Gene expression profiles in the brain predict behavior in individual honey bees. Science 302, 296-299.

Witte, K. \& Nöbel, S. (2011). Learning and mate choice. In Fish Cognition and Behavior (Brown, C., Laland, K. \& Krause, J., eds), pp. 81-107. Oxford: Wiley-Blackwell.

Wolf, C. \& Linden, D. E. J. (2012). Biological pathways to adaptability - interactions between genome, epigenome, nervous system and environment for adaptive behavior. Genes, Brain and Behavior 11, 3-28.

Wolf, M., van Doorn, G. S. \& Weissing, F. J. (2008). Evolutionary emergence of responsive and unresponsive personalities. Proceedings of the National Academy of Sciences of the United States of America 105, 15825-15830.

Wolf, J. B., Bayer, T., Haubold, B., Schilhabel, M., Rosenstiel, P. \& Tautz, D. (2010) Nucleotide divergence vs. gene expression differentiation: comparative transcriptome sequencing in natural isolates from the carrion crow and its hybrid zone with the hooded crow. Molecular Ecology 19(Suppl. 1), 162-175.

Wolf, M., Van Doorn, G. S. \& Weissing, F. J. (2011). On the coevolution of social responsiveness and behavioural consistency. Proceedings of the Royal Society B 278, 440-448.

Wullimann, M. F. \& Mueller, T. (2004). Teleostean and mammalian forebrains contrasted: evidence from genes to behavior. Journal of Comparative Neurology 475, 143-162.

Wurm, Y., Wang, J. \& Keller, L. (2010). Changes in reproductive roles are associated with changes in gene expression in fire ant queens. Molecular Ecology 19, 1200-1211.

Yamamoto, K. \& Vernier, P. (2011). The evolution of dopamine systems in chordates. Frontiers in Neuroanatomy $\mathbf{5}, 21$.

Yang, E. J. \& Wilczynski, W. (2007). Social experience organizes parallel networks in sensory and limbic forebrain. Developmental Neurobiology 67, 285-303.

Zupanc, G. K. H. \& Lamprecht, J. (2000). Towards a cellular understanding of motivation: structural reorganization and biochemical switching as key mechanisms of behavioral plasticity. Ethology 106, 467-477.

\section{Electronic Reference}

Froese, R. \& Pauly, D. (2012). FishBase. Available at www.fishbase.org. 